Article

\title{
Eco-Friendly Photocatalysts for Degradation of Dyes
}

\author{
Gee Een Lau ${ }^{1}\left(0\right.$, Che Azurahanim Che Abdullah ${ }^{1,2, *}$, Wan Amir Nizam Wan Ahmad ${ }^{3}(\mathbb{D}$, \\ Suvik Assaw ${ }^{4}$ and Alvin Lim Teik Zheng ${ }^{5}$ \\ 1 Institute of Advanced Technology (ITMA), Universiti Putra Malaysia, Serdang 43400, Selangor, Malaysia; \\ een_313@hotmail.my \\ 2 Department of Physics, Faculty of Science, Universiti Putra Malaysia, Serdang 43400, Selangor, Malaysia \\ 3 School of Health Sciences, Universiti Sains Malaysia, Health Campus, \\ Kubang Kerian 16150, Kelantan, Malaysia; wanamir@usm.my \\ 4 Faculty of Science and Marine Environment, Universiti Malaysia Terengganu, \\ Kuala Nerus 21030, Terengganu, Malaysia; aasuvik@umt.edu.my \\ 5 Graduate School of Life Science and Systems Engineering, Kyushu Institute of Technology, 2-4 Hibikino, \\ Wakamatsu-ku, Kitakyushu, Fukuoka 808-0196, Japan; alvinltz29@gmail.com \\ * Correspondence: azurahanim@upm.edu.my; Tel.: +60-397-696-675
}

Received: 21 July 2020; Accepted: 19 August 2020; Published: 1 October 2020

\begin{abstract}
In the current era of globalization, synthetic dyes are one of the key factors of water pollution. Photocatalysis constitutes a promising technology for the treatment of wastewater, especially to those containing hard-to-remove organic compounds. Zinc oxide nanoparticles (ZnONPs) play a vital role as a photocatalyst material. This research highlights the synthesized ZnONPs with roselle flower and oil palm leaf extract. The extracts and sodium hydroxide $(\mathrm{NaOH})$ act as reducing agents during the synthesis process. Synthesis without the addition of plant extract is used as blank control for the experiment. Structural and optical studies of the three variants of ZnONPs were performed. High purity of $\mathrm{ZnONPs}$ with element $\mathrm{Zn}$ and $\mathrm{O}$ was obtained. The size of the three variants of ZnONPs was from 10-15 $\mathrm{nm}$ and found in agglomerated spherical shape. Large band gap, $3.2 \mathrm{eV}$ was obtained by UV-Vis and high thermal stability was proven by TGA. Oxygen vacancies that assist in the degradation phenomenon were found in ZnONPs. Five percent of ZnONPs with the presence of $10 \mathrm{~W}$ UV light could effectively degrade $10 \mathrm{ppm}$ MO in $5 \mathrm{~h}$ and MB in $3 \mathrm{~h}$. Besides, high antioxidant properties and low toxicity demonstrated the ability of ZnONPs to be used as photocatalysts. In conclusion, ZnONPs can be further developed for pharmaceutical and industrial use.
\end{abstract}

Keywords: green synthesis; zinc oxide; photocatalytic

\section{Introduction}

More than 8000 chemicals were involved in the process of dyeing and printing in textile manufacturing. Organic dyes are recognized as one of the roots of environmental pollution. In the dyeing process, studies showed that about $80 \%$ of the synthetic dye would remain on the fabric. The rest would go up in the drain, resulting in harmful consequences owing to their toxic nature [1]. Methyl orange (MO) dye with chemical formula $\mathrm{C}_{14} \mathrm{H}_{14} \mathrm{~N}_{3} \mathrm{NaO}_{3} \mathrm{~S}$ is available in orange powder form. $\mathrm{MO}$ can be found in various branches of textile, leather, and paper printing industries. Nevertheless, improper usage and disposal of MO may bring adverse effects. Especially toward the human body and environment [2]. Methylene blue (MB) is another basic synthetic dye commonly used in medical treatment. For instance, it applies to anti-malaria because of their unique properties [3].

Although the acute toxicity of $\mathrm{MB}$ is not serious, the dye may have detrimental effects on aquatic life. This is due to their complex aromatic compounds. In this case, sunlight cannot penetrate well into 
the water. This will inhibit the development of aquatic animals and plants [4]. Various techniques have been employed for the treatment of organic molecules in dye water. The approach includes chemical, physical, biological, and their combinations [5]. Some of these methods were not efficient in some cases. For instance, the chemical methods using activated carbon are very effective in removing the synthetic dye. However, it is suitable for treating only small effluent volume. Besides, the operation requires a long time and high capital cost [6]. Physical techniques like coagulation, flocculation, and reverse osmosis were previously implemented. The major drawback of these techniques is the formation of secondary waste products.

Biological treatments need strict control on temperature and $\mathrm{pH}$. The degradation of synthetic dye took a long process and disposal of a large amount of sludge. Particularly, photocatalysts are extensively executed and act as a promising alternative. Photocatalysts are capable in degrading various organic pollutants or dyes. They harness light energy to excite the photo-induced electrons. The photo-generated electrons from conduction band $(\mathrm{CB})$ were transferred to the valence band (VB) resulting in recombination of the charge carrier to form $\mathrm{H}_{2} \mathrm{O}$ molecules. Meanwhile, the $\mathrm{H}_{2} \mathrm{O}$ molecules were oxidized in $\mathrm{VB}$ to increase the amount of $\bullet \mathrm{OH}$ produced to degrade the synthetic dyes. In photo oxidation, complete oxidation of organic pollutants take place within short periods.

Moreover, this process does not involve any formation of secondary hazardous products. It only requires highly active and inexpensive catalysts which are functionalized in specially designed reactor systems [7]. $\mathrm{ZnO}$ is instigated as a photocatalyst to enhance the degradation efficiency of $\mathrm{MO}$ and MB. It is well-known for its wide band gap, approximately $3.3 \mathrm{eV}$. This property allows it to be active in the presence of UV light. It has large room temperature photoinduced electron-hole pairs. The binding energy between the pairs is $60 \mathrm{meV}$ [8]. Nanoformulated $\mathrm{ZnO}$ draws worldwide attention among researchers because of their exclusive optical and chemical behaviors. Previous studies mostly focus on $\mathrm{ZnO}$ nano size and morphology [9]. Owing to their abundance and not toxic, numerous scientists investigated the ability of ZnONPs as photocatalysts. ZnONPs is an effective photocatalyst in dye degradation of organic pollutants as it produces hydrogen peroxide $\left(\mathrm{H}_{2} \mathrm{O}_{2}\right)$ and has capability in mineralizing the organic chemicals to carbon dioxide $\left(\mathrm{CO}_{2}\right)$ and mineral acids [10]. In 2015, Nethravathi et al. reported the green synthesis ZnONPs using Garcinia xanthochymus fruit is effective for photodegradation. 94.1\% photodegradation is achieved with the presence of $200 \mathrm{mg} \mathrm{ZnONPs}$ in $100 \mathrm{~mL} 5 \mathrm{ppm}$ MB under UV irradiation [11]. From their study, it can be observed that $2 \mathrm{mg} / \mathrm{mL}$ of $\mathrm{ZnO}$ is required to act as a catalyst for the photodegradation. In this study, a lower amount of catalysts will be used to degrade a large-scale synthetic dye. Besides, ZnONPs have exceptional stability in a variety of conditions [12]. Extensive researches investigated the stability of ZnONPs, as it is essential to evaluate the stability of catalysts for practical application. In a large-scale operation, photocatalysts thermal stability is vital as temperature may change according to the season. High cost is needed to maintain a constant temperature, especially for the system, which relies on visible light photocatalytic degradation. The exposure to sunlight or high-intensity light source might fluctuate the temperature [13]. In 2014, Chen et al. reported that the $\mathrm{ZnO}$ nanosphere exhibited excellent good thermal stability in the whole thermal process from $50{ }^{\circ} \mathrm{C}$ to $800{ }^{\circ} \mathrm{C}$.

In nanotechnology, photocatalysts can be fabricated in various techniques. Several recent reports focused on synthesizing metal oxides using physical and chemical methods. These include sol-gel, hydrothermal, chemical precipitation, thermal decomposition, and chemical bath deposition methods [14]. However, the presence of some toxic chemicals that adsorbed on the surface of photocatalysts may bring adverse effects to aquatic systems. Furthermore, most of the preparation of the catalysts by chemical and physical methods require high temperature and pressure for their initiation, while inert conditions may be required for some reactions. In short, most of the chemicals and precursors used for the chemical synthesis and their stabilization are toxic and lead to non-ecofriendly by products [15].

Green technology plays a vital role in the economy and environment. The development of green technology helps us to get rid of the mitigation of environmental degradation. Usage of agriculture waste materials to synthesize nanoparticles was a recent trend in the era of research. 
Introduction of plant extracts instead of hazardous chemicals made it eco-friendly and cost-effective. Roselle flower (Hibiscus sabdariffa Linn) is a dark red color medicinal flower with worldwide fame. The phenol compounds and flavonoids contained in roselle flowers are very high. Indirectly, antioxidants such as anthocyanin and ascorbic acid are proven to be high in the roselle flower [16]. Another agriculture waste of interest is oil palm wastes. Oil palm has witnessed a remarkable and sustained global market. Simultaneously, tons of lignocellulose biomass are generated from the oil palm industries, and this includes oil palm leaf. The improper disposal of these biomass is one of the alarming issues. Researchers are looking for a method of technological, cost-effective, and environmental considerations. This will help in resolving the plenty of oil palm waste [17].

Previous research has shown that oil palm leaf has antioxidant activity. On top of that is the antimicrobial effect on Gram-positive bacteria. The phytochemicals present in roselle flower and oil palm leaf extracts are important for the size reduction process. They act as stabilizing and reducing agents for the synthesis of ZnONPs to control the size and shape [18]. In the particular system, decreasing the size of particles may increase the rate of interfacial charge transfer. The large surface areas for photogenerated charge carriers will react with absorbed molecules. This will then form hydroxyl and superoxide radicals [19]. ZnONPs from oil palm leaf, $\mathrm{ZnO}(\mathrm{O})$ and roselle, $\mathrm{ZnO}(\mathrm{R})$ are expected to have high potential applications. For topical application, it can be used as sunscreen and skin lightening agent [20].

Currently, there is no report related to the synthesis of ZnONPs with oil palm leaf extract for water degradation. In this research, a chemically synthesized mixture (zinc acetate dihydrate and sodium hydroxide only) was used as comparative analysis, $\mathrm{ZnO}(\mathrm{B})$. The products of this research, synthesized $\mathrm{ZnO}(\mathrm{R}), \mathrm{ZnO}(\mathrm{O})$, and $\mathrm{ZnO}(\mathrm{B})$ are used as photocatalysts for dye degradation. Photocatalytic activity has been carried out to demonstrate the capability of these catalysts. On top of that, the toxicity and antioxidant properties were also tested to ensure the products were environmentally friendly.

\section{Results}

\subsection{Morphology}

Scanning electron microscopy (SEM) images from Figure 1a-c showed that the synthesized ZnONPs had agglomerated. The mapping images manifested that $\mathrm{Zn}$ enriched in most of the regions. While energy dispersive X-ray (EDX) had revealed the elemental distribution characteristics. This had further confirmed the purity of ZnONPs. The EDX results showed that the samples consisted of zinc and oxygen. Zn composed $89.70 \%$ in $\mathrm{ZnO}$ synthesized with oil palm leaf extract, $\mathrm{ZnO}(\mathrm{O})$. The composition was highest among $\mathrm{ZnO}$ with roselle flower extract, $\mathrm{ZnO}(\mathrm{R})$ and without plant extract, $\mathrm{ZnO}(\mathrm{B})$. This finding shows the presence of plant extracts helping in producing high purity products [21]. The purity of $\mathrm{ZnO}(\mathrm{R})$ and $\mathrm{ZnO}(\mathrm{O})$ were higher compared to the previous research done by Hasnidawani et al. in 2016 [22].

Transmission electron microscopy (TEM) was used to observe the size, shape, and morphology of synthesized ZnONPs. Figure 2(a1,a2) shows that most of the $\mathrm{ZnO}(\mathrm{B})$ nanoparticles were spherical in shape, yet, strongly agglomerated with average size, $15.51 \pm 2.82 \mathrm{~nm}$. In Figure 2(b1-c2) the agglomeration was slightly reduced. This may vary due to the addition of roselle flower extract and oil palm leaf extract as reducing agents. The plant extracts are rich in biomolecules and metabolites such as proteins, vitamins, coenzymes-based intermediates, phenols, flavonoids, and carbohydrates. These metabolites contain hydroxyl, carbonyl, and amine functional groups. These functional groups will react with the metal ions and reduce the size of ZnONPs [23]. Besides, the average sizes of the $\mathrm{ZnO}(\mathrm{R}), 9.85 \pm 1.50 \mathrm{~nm}$ and $\mathrm{ZnO}(\mathrm{O}), 10.88 \pm 2.43 \mathrm{~nm}$ were smaller than those of $\mathrm{ZnO}(\mathrm{B})$. The results obtained were consistent with the previous research carried out by Osuntokun et al. in 2019, which compared the size of synthesized nanoparticles with and without aqueous broccoli extract by TEM [24]. 
(a)
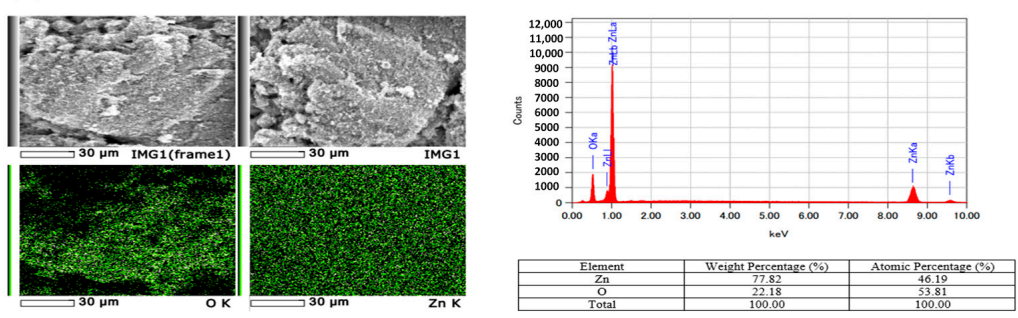

(b)
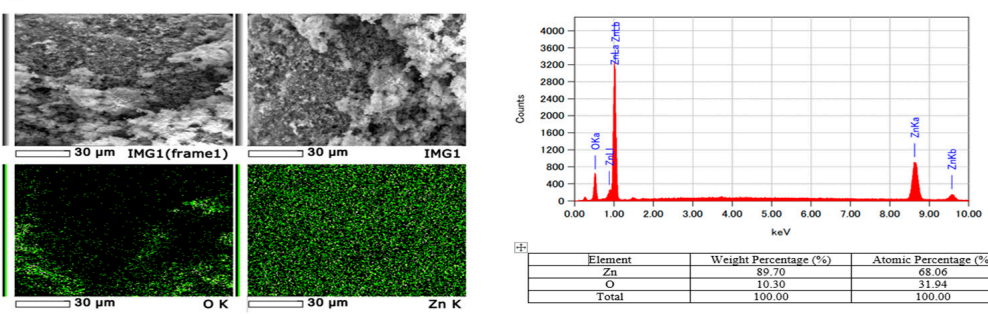

(c)
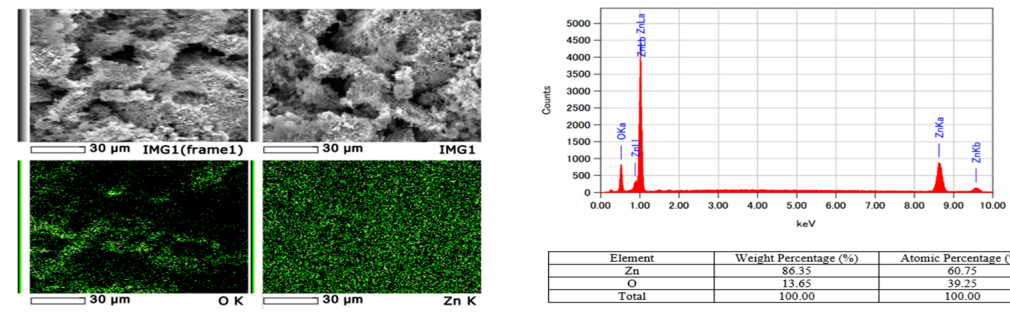

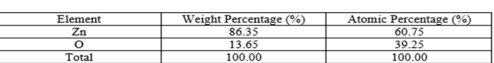

Figure 1. SEM mapping image and EDX spectrum of synthesized ZnONPs: (a) ZnO (B); (b) ZnO (O); (c) $\mathrm{ZnO}(\mathrm{R})$.
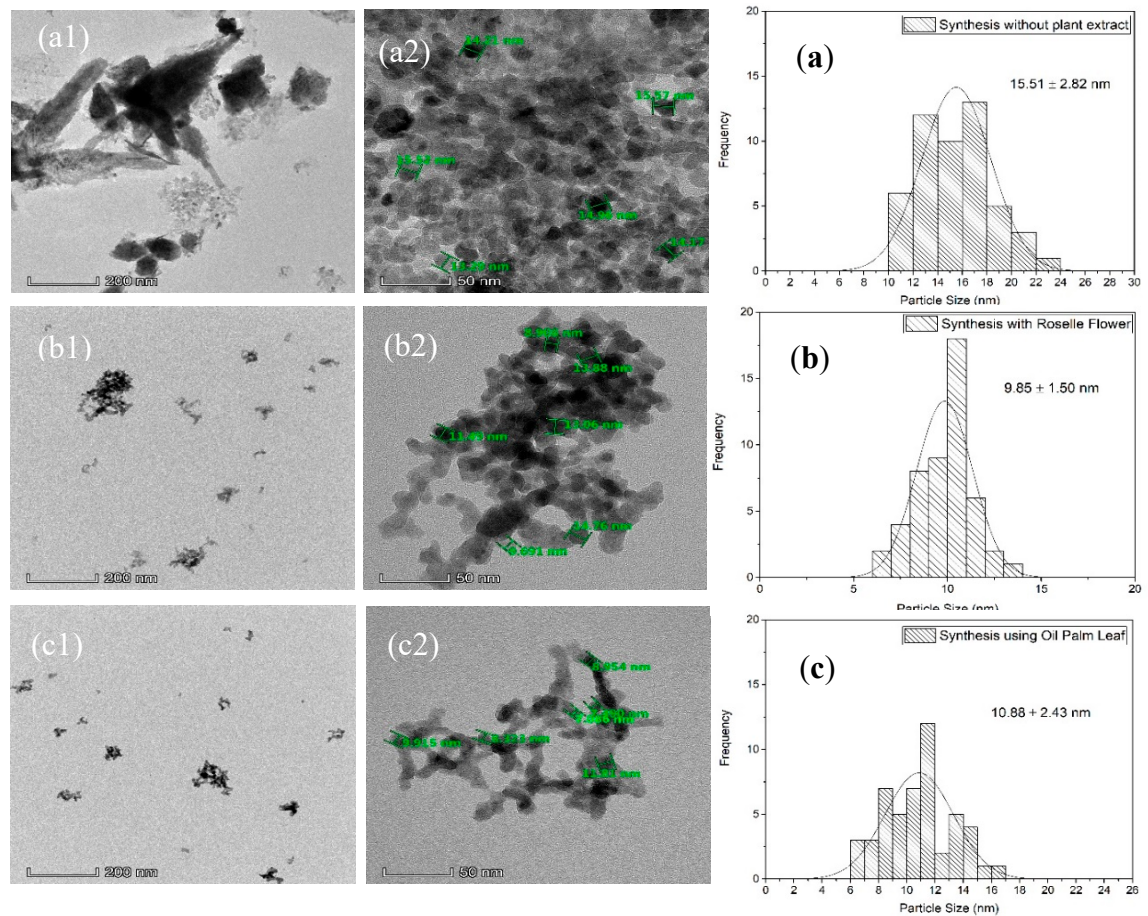

Figure 2. TEM image and average size of synthesized ZnONPs: (a) ZnO (B); (b) ZnO (R); (c) ZnO (O). 


\subsection{X-ray Diffractometer (XRD)}

The XRD spectra of $\mathrm{ZnO}(\mathrm{R})$ and $\mathrm{ZnO}(\mathrm{O})$ in Figure 3 showed that they were metal oxide with pure hexagonal structure. The crystallite size for $\mathrm{ZnO}(\mathrm{B}), \mathrm{ZnO}(\mathrm{R})$, and $\mathrm{ZnO}(\mathrm{O})$ was $31.40 \mathrm{~nm}, 19.59 \mathrm{~nm}$, and $20.65 \mathrm{~nm}$ respectively. The peaks revealed at $2 \theta$ range correspond to pure $\mathrm{ZnO}$. Among the three spectra, the highest intensity peak was (101) planes of ZnO. Other smaller intensity peaks, 100, 002, 102, 110, 103, 200, 112, and 201 were observed. The results obtained were in agreement with the previous research done by Chaudhary et al. [25]. No other irrelevant peaks for $\mathrm{ZnO}(\mathrm{R})$ and $\mathrm{ZnO}(\mathrm{O})$ were observed. These had further confirmed the presence of plant extracts in assisting in the production of highly pure ZnONPs [26]. Oppositely, some small unrelated peaks were observed from the spectra of $\mathrm{ZnO}$ (B). It indicated that the formation was not as successful as the one with the presence of plant extract as a reducing agent. The explanation was agreed with the results obtained by Hassan et al. [27].

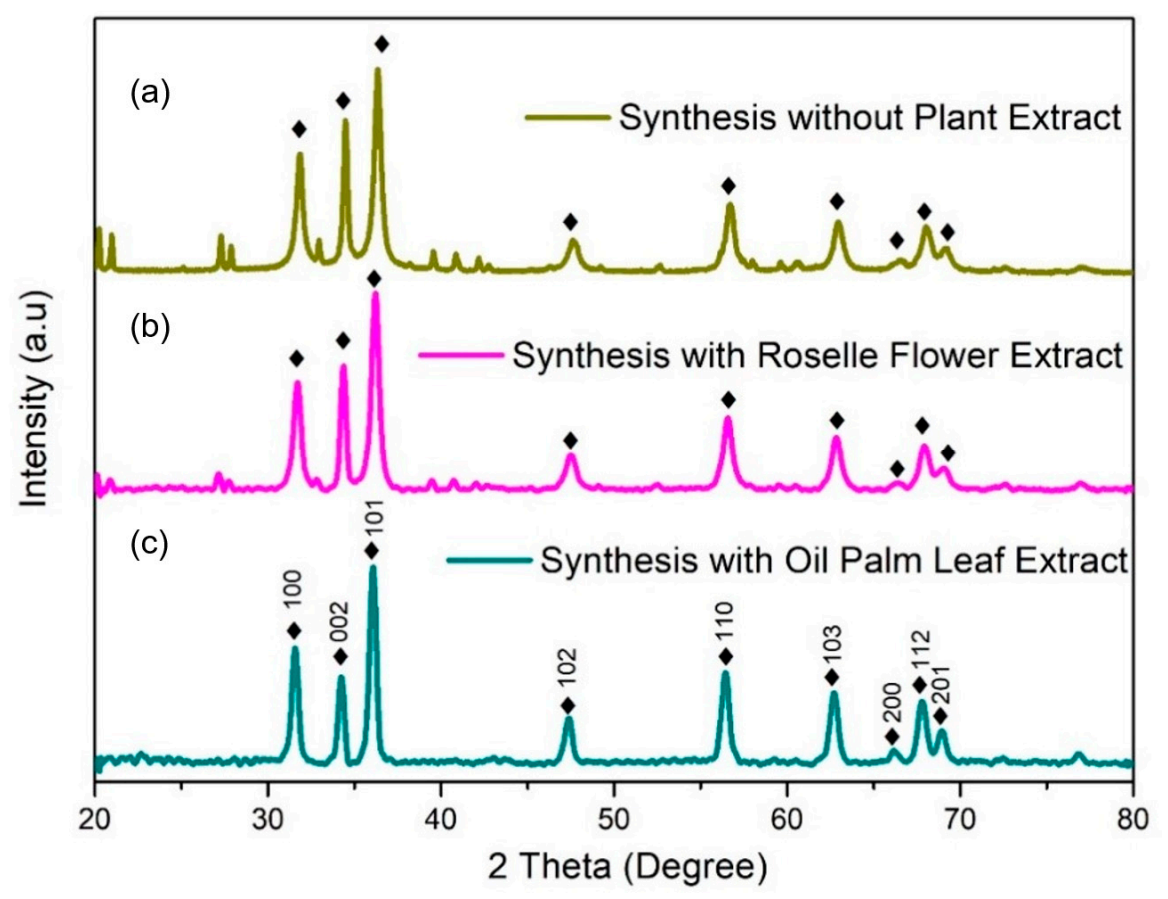

Figure 3. XRD spectra of synthesized ZnONPs: (a) $\mathrm{ZnO}(\mathrm{B})$; (b) $\mathrm{ZnO}(\mathrm{R})$; (c) $\mathrm{ZnO}(\mathrm{O})$.

\subsection{Fourier Transform Infrared Spectroscopy (FTIR)}

The functional group of ZnONPs were identified using FTIR in the range of $4000 \mathrm{~cm}^{-1}$ to $400 \mathrm{~cm}^{-1}$ as shown in Figure 4. O-H stretching group that can be found between 3200 and $3600 \mathrm{~cm}^{-1}$ was observed in three of the ZnONPs. However, ZnONPs with plant extracts exhibited broader band regions than without plant extract. During transformation of zinc acetate dihydrate into ZnONPs, the compounds in the plant extract act as chelating and capping agents [28]. The plant extracts possess rich biomolecules and metabolites. These include proteins, phenols, flavonoids, and carbohydrates. The flavonoids contain several functional groups that include $\mathrm{O}-\mathrm{H}$ functional groups. This bond is responsible for the reduction of metal ions in the formation of ZnONPs. Besides, Zn-O stretching vibration could be observed in the range of $400-600 \mathrm{~cm}^{-1}$. This stretching vibration had confirmed the successful formation of ZnONPs [29]. Two strong bands were observed from a spectrum of ZnONPs with both plant extracts at $1583 \mathrm{~cm}^{-1}$ and $1405 \mathrm{~cm}^{-1}$. These bonds occurred because of glycosidic linkage of $\mathrm{C}-\mathrm{O}-\mathrm{C}$ and secondary alcoholic groups. The alcoholic groups include phenolic compounds, flavonoids, and amines which are in high content in the plant extracts. These active compounds act as stabilizing agents for the synthesis of ZnONPs [30]. The bands at $1093 \mathrm{~cm}^{-1}$ and $1024 \mathrm{~cm}^{-1}$ are associated to $\mathrm{C}-\mathrm{O}$ [31], while $719 \mathrm{~cm}^{-1}$ represented out of plane bending of aromatic $\mathrm{C}-\mathrm{H}$ bond [32]. 


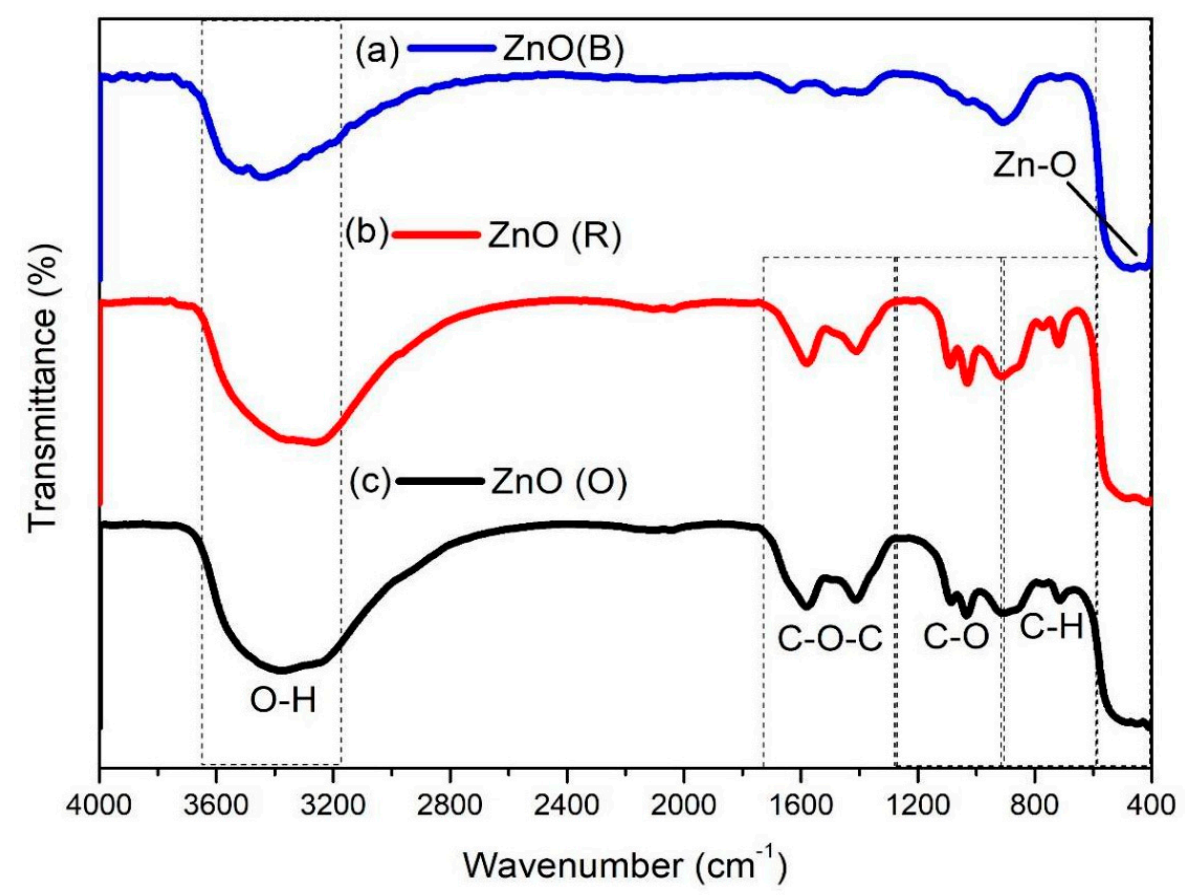

Figure 4. FTIR spectra of synthesized ZnONPs: (a) $\mathrm{ZnO}$ (B); (b) $\mathrm{ZnO}$ (R); (c) $\mathrm{ZnO}(\mathrm{O})$.

\subsection{Ultraviolet-Visible Spectorscopy (UV-Vis)}

The formation of ZnONPs was confirmed with UV-Vis. Figure 5 shows the UV-Vis spectra of $\mathrm{ZnONPs}$ revealed strong absorption peaks at $357 \mathrm{~nm}, 359 \mathrm{~nm}$, and $365 \mathrm{~nm}$ on $\mathrm{ZnO}(\mathrm{B}), \mathrm{ZnO}(\mathrm{O})$, and $\mathrm{ZnO}(\mathrm{R})$ respectively. The obtained wavelengths were in line with previous work done by Patil et al. in 2016 [33]. The energy difference between the valence band and the conduction band is an indicator of the band gaps energy, E. The band gaps, as shown in Table 1 and Figure 5 were found to be between $2.90 \mathrm{eV}$ and $3.20 \mathrm{eV}$ by using Tauc Plot. These obtained band gaps were approximate to $3.38 \mathrm{eV}$ obtained by Varughese et al. in 2015 [34].

$$
(\alpha h v)^{n}=K\left(h v-E_{g}\right)
$$

where $\alpha$ is the absorption coefficient, hv is the incident photon energy. $\mathrm{K}$ is the energy-independent constant. $\mathrm{E}_{\mathrm{g}}$ is the optical band gap in nanoparticles and $\mathrm{n}$ is the nature of transition. The optical property strongly depends on the particle size. Quantum confinement arises from the size reduction of material which leads to electronic wave functions, which may result in changes associated with the electronic and optical properties of the nanomaterials. Smaller particle size results in stronger quantum confinement. It causes increment in the energy band gap and the band structure of the material is modified [35]. Owing to this fact, the higher the value of $\lambda_{\max }$, the larger the size of the nanoparticles. This causes reduction in band gap energy and leads to the red shift [36]. Oppositely, for a small size of nanoparticles, the wavelength decreases and causes increment in band gap energy leading to the blue shift. The peaks in the spectra represent the discrete excited electronic states [37]. The sharp peaks in the absorption spectra also imply that the particles are nanosized with narrow particle size distribution. The peak was shifted away from $\mathrm{ZnO}(\mathrm{R})$ to $\mathrm{ZnO}(\mathrm{O})$ and $\mathrm{ZnO}(\mathrm{B})$ [38]. Theoretically, the difference in the band gap energy originated from the smaller size of $\mathrm{ZnO}(\mathrm{R})$ and $\mathrm{ZnO}(\mathrm{O})$ compared to $\mathrm{ZnO}$ (B). However, for the analysis of UV-Vis absorption, the ZnONPs were prepared in colloidal solution. During the preparation of colloidal solution, the agglomeration might occur. There will be errors during investigation of polydisperse ZnONPs [39]. Thus, the size of the nanoparticles obtained from transmission electron microscope, TEM will be more reliable compared to UV-Vis. 


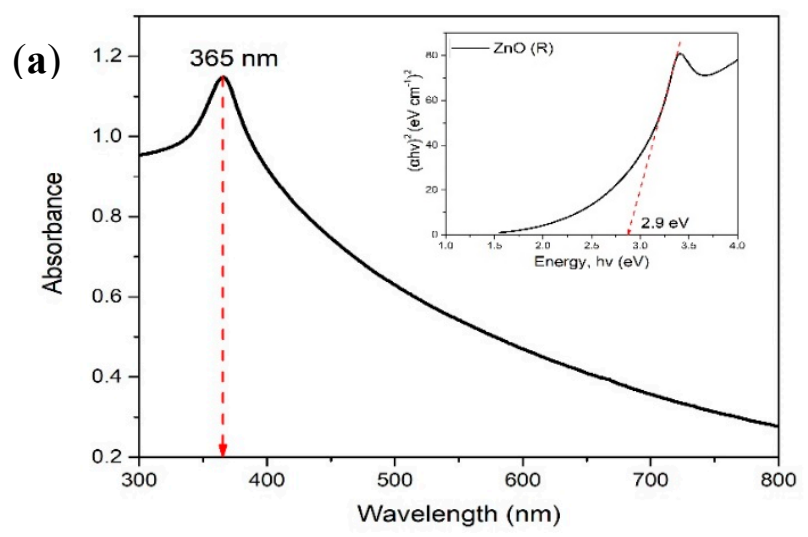

(b)

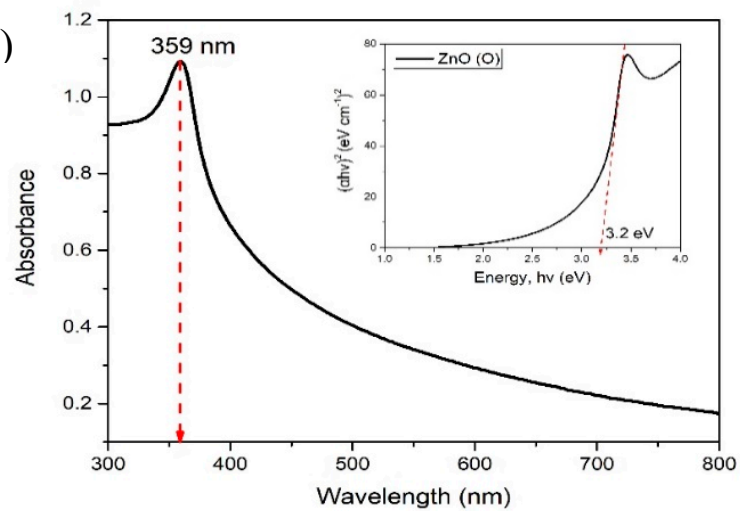

(c)

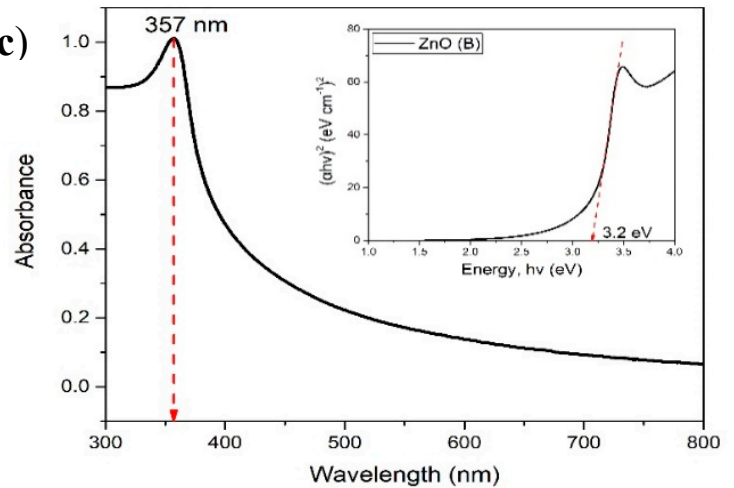

Figure 5. UV-Vis and band gap spectra of synthesized ZnONPs: (a) ZnO (R); (b) ZnO (O); (c) ZnO (B).

Table 1. Band gap energy and the wavelength maximum of synthesized ZnONPs: (a) ZnO (R); (b) ZnO (O); $\mathrm{ZnO}(\mathrm{B})$.

\begin{tabular}{ccc}
\hline Sample Material & Band Gap Energy E (eV) & Wavelength Maximum $\boldsymbol{\lambda}_{\max }(\mathbf{n m})$ \\
\hline $\mathrm{ZnO}(\mathrm{R})$ & 2.90 & 365 \\
$\mathrm{ZnO}(\mathrm{O})$ & 3.20 & 359 \\
$\mathrm{ZnO}(\mathrm{B})$ & 3.20 & 357 \\
\hline
\end{tabular}

\subsection{Thermogravimetric Analysis (TGA)}

TGA was carried out in the range of 30 to $550{ }^{\circ} \mathrm{C}$ with an $\mathrm{N}_{2}$ atmosphere. Thermal decomposition behavior of $\mathrm{ZnONPs}$ was investigated, as shown in Figure 6. The total weight loss percentage for synthesized $\mathrm{ZnO}(\mathrm{B}), \mathrm{ZnO}(\mathrm{R})$, and $\mathrm{ZnO}(\mathrm{O})$ was $4 \%$, 6\%, and $9 \%$ respectively. The first drastic degradation step occurred at around $150{ }^{\circ} \mathrm{C}$. This phenomenon occurred due to the evaporation of surface adsorbed water. After $200{ }^{\circ} \mathrm{C}$, the degradation of synthesized $\mathrm{ZnO}(\mathrm{R})$ and $\mathrm{ZnO}(\mathrm{O})$ were 
slightly larger than $\mathrm{ZnO}$ (B). The gradual degradation that occurs in the curve of $\mathrm{ZnO}$ (B) happens due to the decomposition of condensation dehydration of the hydroxyls. The weight loss of the synthesized $\mathrm{ZnO}(\mathrm{R})$ and $\mathrm{ZnO}(\mathrm{O})$ after $200{ }^{\circ} \mathrm{C}$ were higher compared to $\mathrm{ZnO}(\mathrm{B})$. This difference may indicate the degradation of the existing organic material. For instance, polyphenols and natural pigments have been found in both plants. The findings of thermal decomposition behavior were consistent with the previous experiment conducted by Hassan et al. in 2018 [27]. The total average sample weight loss for $\mathrm{ZnO}(\mathrm{B}), \mathrm{ZnO}(\mathrm{R})$, and $\mathrm{ZnO}(\mathrm{O})$ are $4 \%, 7 \%$, and $9 \%$ respectively of the material weight. The differences of weight loss of the material weight are minuscule. The weight loss has no profound effect on the thermal stability of three variants of ZnONPs. High stability catalysts and simplicity preparation techniques bring advantages especially to countries with hot climates, as three variants of ZnONPs will not be decomposed in the range of 0 to $500{ }^{\circ} \mathrm{C}$. This property represents significant advance on the design of thermally stable photocatalysts for applications which require the catalyst to undergo high temperature processing or endure extreme operating conditions [40].

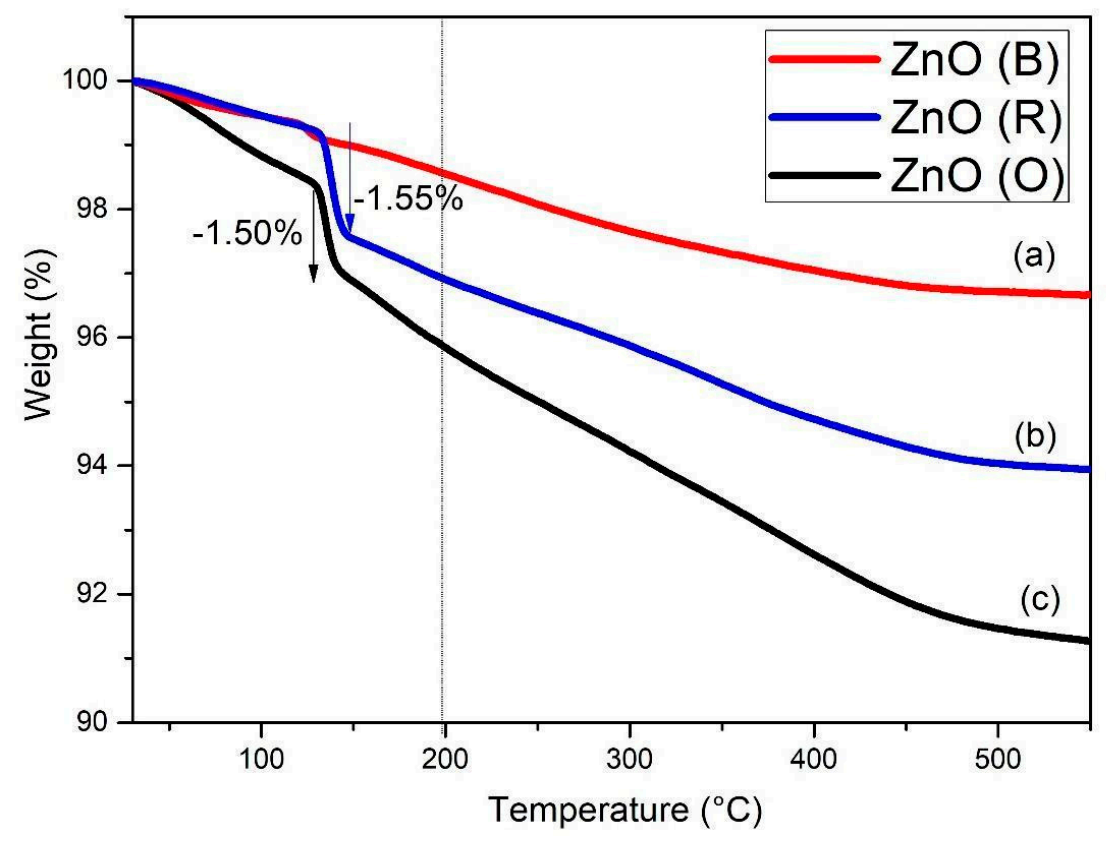

Figure 6. Thermogravimetric analysis (TGA) for synthesized ZnONPs: (a) ZnO (B); (b) with ZnO (R); (c) $\mathrm{ZnO}(\mathrm{O})$.

\subsection{Electron Spin Resonance (ESR)}

The presence of unpaired electrons in synthesized ZnONPs was studied by ESR. From Figure 7, the g-factor values observed from the broad ESR spectra of synthesized ZnONPs were almost the same. The values obtained are 1.94, 1.92, and 2.00 respectively. These values associate these lines to a defect in zinc oxide. The signal which localized at these values was attributed to oxygen vacancies [41]. From the figure, $\mathrm{ZnO}(\mathrm{R})$ showed the largest concentration of defects associated with oxygen vacancies. However, $\mathrm{ZnO}(\mathrm{B})$ and $\mathrm{ZnO}(\mathrm{O})$ imparted the presence of vacancies but with lower concentration. Oxidation and reduction take place during photocatalytic activity. The presence of defects or vacancies had shown that ZnONPs have the potential to work as a photocatalyst [42]. 


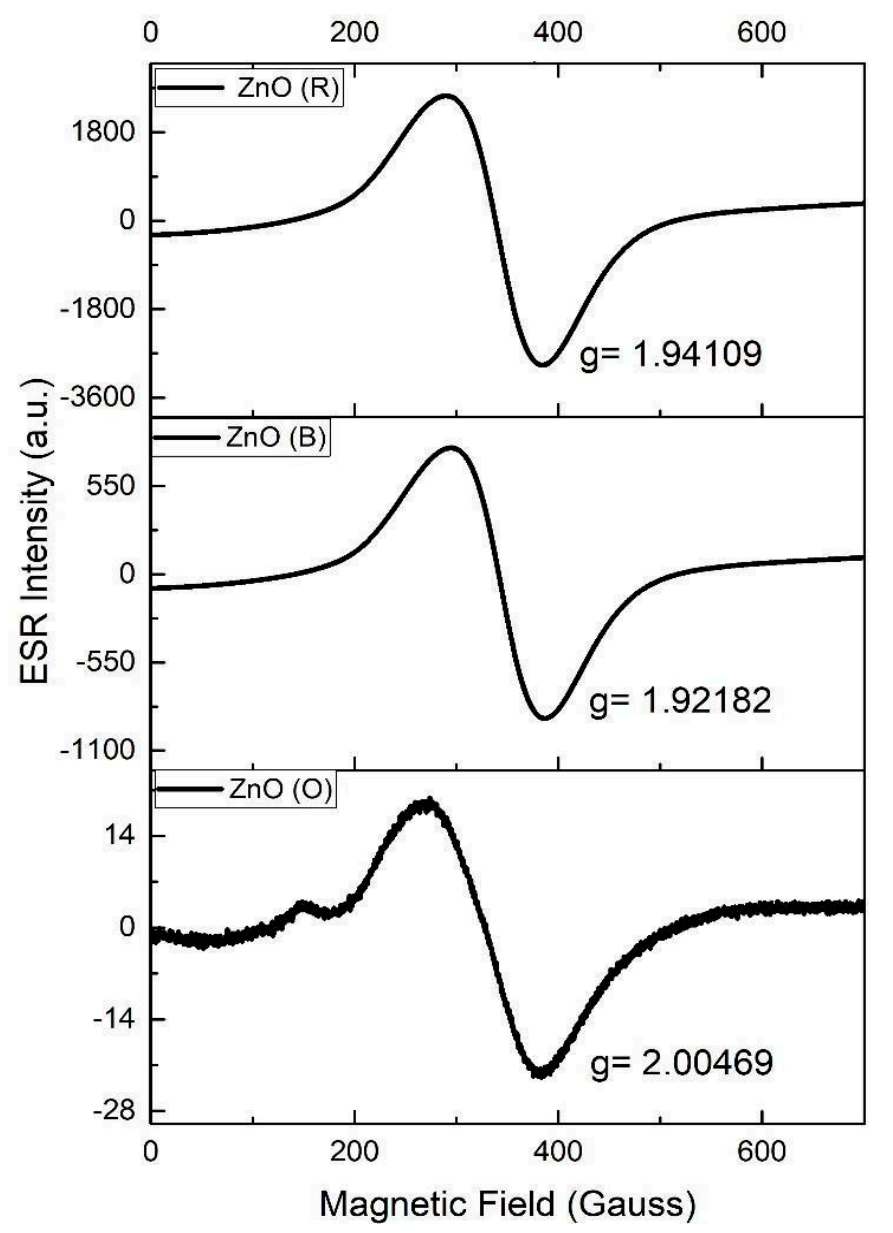

Figure 7. ESR spectra for synthesized ZnONPs.

\subsection{Photocatalytic Activity}

Different chemical structures in $\mathrm{MO}$ and $\mathrm{MB}$ dye solution have resulted in their use in this research. The degradation efficiency of synthesized ZnONPs as photocatalyst was compared in this research. $\mathrm{MO}$ is anionic dye, whereas MB is cationic dye. The differences in reaction and degradation efficiency have been investigated. The presence of UV light excited the electrons. The excited electrons move from valence band (VB) to conduction band (CB). In this case, holes were created in the valence band because of the vacancy of the transferred electron. The electron reduced the surface of the adsorbed $\mathrm{O}_{2}$ into anionic superoxide radical, $\bullet \mathrm{O}_{2}{ }^{-}$. Subsequently, the surface of $\mathrm{ZnONPs}$ became positive. These free radical ions, $\bullet \mathrm{O}_{2}{ }^{-}$and $\bullet \mathrm{OH}$ then oxidized the organic pollutants of the dye. They turn into small intermediates and final products such as $\mathrm{H}_{2} \mathrm{O}$ and $\mathrm{CO}_{2}$ [43].

Figure $8 \mathrm{~b}$ showed that the degradation of $\mathrm{MO}$ dye after $5 \mathrm{~h}$ of exposure to UV was only $63 \%$ without the presence of $\mathrm{ZnONPs}$. The synthesized $\mathrm{ZnO}(\mathrm{B}), \mathrm{ZnO}(\mathrm{O})$, and $\mathrm{ZnO}(\mathrm{R})$ were used as catalysts in this study. The kinetic study showed the system irradiated by UV reached degradation efficiency of $100 \%, 99 \%$, and $97 \%$, respectively, within $5 \mathrm{~h}$. Degradation curve of the photocatalytic activity can be found in supplementary materials (Figures S1 and S2). The results obtained seem to be more efficient than previous research by Kazeminehad and Sadollahkhani (2016). The previous study was conducted by adding $0.05 \mathrm{~g}$ ZnONPs into $100 \mathrm{~mL}$ of $20 \mathrm{mg} / \mathrm{L}$ aqueous dye solution. The photocatalytic decompositions of the dye took $240 \mathrm{~min}$ to achieve $83 \%$ degradation [44]. The results in Figure 8a showed that the degradation of $\mathrm{ZnO}(\mathrm{B})$ was slightly faster compared to $\mathrm{ZnO}(\mathrm{R})$ and $\mathrm{ZnO}(\mathrm{O})$. However, the findings revealed the degradation percentage was similar and can be concluded to be capable of fully degrading the tested dye. It has clearly shown that a small amount of ZnONPs $(5 \%$ or $40 \mathrm{mg}$ ) has a great ability to degrade large scale $(800 \mathrm{~mL})$ of $\mathrm{MO}$ under low UV irradiation. 

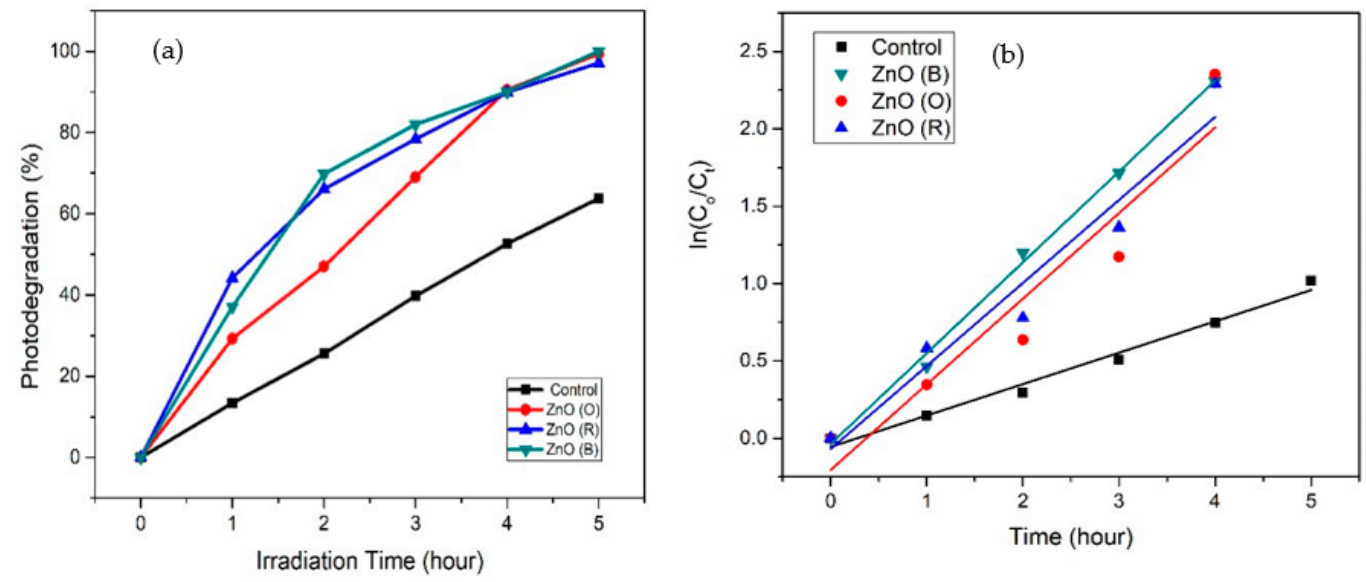

Figure 8. (a,b): Process of degradation of MO dyes with irradiation in the UV region.

The photocatalytic reactions have been performed using the pseudo first-order kinetics, as shown in Equation (2):

$$
\ln \left(\mathrm{C}_{0} / \mathrm{C}_{\mathrm{t}}\right)=\mathrm{kt}
$$

where $C_{0}, C_{t}, k$, and $t$ represent the initial concentrations of $M B$, the concentration of $M B$ at time $t$, observed pseudo-first-order rate coefficients, respectively. The plot of $\ln \left(C_{0} / C_{t}\right)$ versus time of irradiation for the control and three variants photocatalytic activity were plotted in Figure $8 \mathrm{~b}$. The rate of constants and the corresponding correlation coefficients $\left(R^{2}\right)$ were obtained from the plots and tabulated into Table 2. The results obtained provide correlation coefficients in the range of $0.9076<\mathrm{R}^{2}<0.9964$. $\mathrm{ZnO}$ (B) showed the highest kinetic rate, $0.5868 \mathrm{~h}^{-1}$, which is 2.89 times for the control activity.

Table 2. Kinetic data of MO dye.

\begin{tabular}{cccccc}
\hline $\begin{array}{c}\text { Photocatalytic } \\
\text { Activity }\end{array}$ & $\begin{array}{c}\text { Photodegradation } \\
\text { of } \mathbf{M O}(\mathbf{\%})\end{array}$ & $\begin{array}{c}\text { Kinetic } \\
\text { Constant, } \mathbf{k}\end{array}$ & $\begin{array}{c}\text { Regression } \\
\text { Coefficient } \mathbf{R}^{\mathbf{2}} \text { ) }\end{array}$ & $\begin{array}{c}\text { 95\% Confidence } \\
\text { Interval Low }\end{array}$ & $\begin{array}{c}\mathbf{9 5 \%} \text { Confidence } \\
\text { Interval High }\end{array}$ \\
\hline Control & 63 & 0.2028 & 0.9841 & 0.1670 & 0.2385 \\
\hline $\mathrm{ZnO}(\mathrm{B})$ & 100 & 0.5868 & 0.9964 & 0.5213 & 0.6520 \\
\hline $\mathrm{ZnO}(\mathrm{R})$ & 97 & 0.5533 & 0.9076 & 0.2289 & 0.8778 \\
\hline $\mathrm{ZnO}(\mathrm{O})$ & 99 & 0.5364 & 0.9512 & 0.3132 & 0.7596 \\
\hline
\end{tabular}

The photodegradation of MB was shown in Figure $9 \mathrm{~b}$ after exposure to $10 \mathrm{~W}$ UV lamp. The rate of degradation was high at $97 \%$, but it took a long period of $5 \mathrm{~h}$ to reach $97 \%$ of the degradation. The presence of $\mathrm{ZnONPs}$, especially $\mathrm{ZnO}(\mathrm{O})$, was successful in accelerating the process of photodegradation of MB dye. After $3 \mathrm{~h}$, all the MB dye with the help of the synthesized ZnONPs as a catalyst had completely degraded. Following the addition of $\mathrm{ZnO}(\mathrm{B})$ and $\mathrm{ZnO}(\mathrm{R})$, the rate of degradation was $99 \%$ and $98 \%$ within $4 \mathrm{~h}$. MB achieved $100 \%$ degradation within a very short period, which is $3 \mathrm{~h}$ as $\mathrm{ZnO}(\mathrm{O})$ added. From Figure 9a, it can be observed that the addition of $\mathrm{ZnO}(\mathrm{R})$ as catalyst showed slightly lower degradation rate in comparison to $\mathrm{ZnO}(\mathrm{B})$ and $\mathrm{ZnO}(\mathrm{O})$. This may happen because of the presence of roselle flower extract in $\mathrm{ZnO}(\mathrm{R})$ because the catalysts are slightly acidic. Ngu yen et al. stated that the $\mathrm{pH}$ effect on $\mathrm{MB}$ degradation is stronger than $\mathrm{MO}$. The change of surface charge of the $\mathrm{ZnO}(\mathrm{R})$ with $\mathrm{pH}$ leads to different extents of repulsion force between the dye molecules and the catalysts. Indirectly, the photocatalytic activity of the catalysts is affected since $\mathrm{OH}$ radicals at the $\mathrm{ZnO}(\mathrm{R})$ surface are more difficult to attack the pollutant molecules. This will then cause the degradation rate to decrease [45]. 

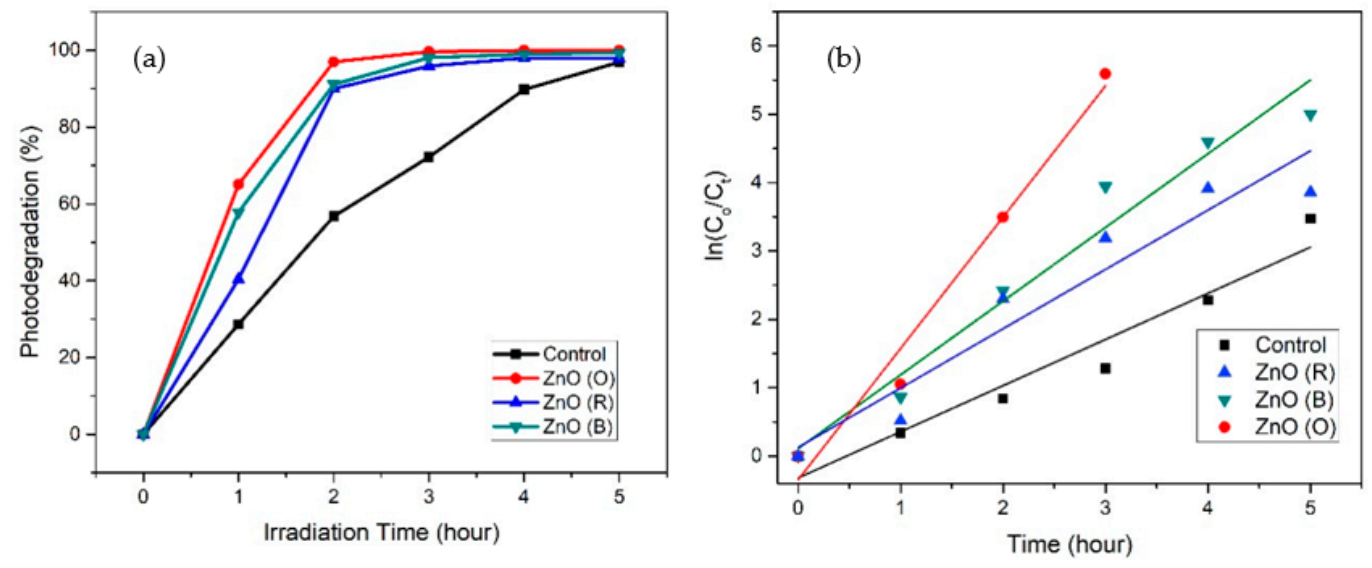

Figure 9. $(\mathbf{a}, \mathbf{b})$ Process of degradation of MB dyes with radiation in the UV region.

To quantify differences in degradation rates, degradations of MB dye were employed to obtain pseudo first-order kinetic constants as shown in Figure 9b. Table 3 shows the kinetic constant of different photocatalytic activity on MB dye. The correlation coefficients were proposed as a good criterion for selecting a kinetic model [46]. The pseudo first-order equation of MB provides a high regression coefficient, $\mathrm{R}^{2}$ which is approximately or more than 0.957 . Kinetic data of MO revealed that $\mathrm{ZnO}(\mathrm{O})$ exhibited highest photocatalytic activity, with a kinetic constant $1.9213 \mathrm{~h}^{-1}$, roughly 2.8 times that for control photocatalytic activity.

Table 3. Kinetic data of MB dye.

\begin{tabular}{cccccc}
\hline $\begin{array}{c}\text { Photocatalytic } \\
\text { Activity }\end{array}$ & $\begin{array}{c}\text { Photodegradation } \\
\text { of } \mathbf{M B}(\mathbf{\%})\end{array}$ & $\begin{array}{c}\text { Kinetic } \\
\text { Constant, } \mathbf{k}\end{array}$ & $\begin{array}{c}\text { Regression } \\
\text { Coefficient } \mathbf{R}^{\mathbf{2}} \mathbf{)}\end{array}$ & $\begin{array}{c}\text { 95\% Confidence } \\
\text { Interval Low }\end{array}$ & $\begin{array}{c}\text { 95\% Confidence } \\
\text { Interval High }\end{array}$ \\
\hline $\mathrm{Control}$ & 96 & 0.6751 & 0.9407 & 0.4397 & 0.9104 \\
\hline $\mathrm{ZnO}(\mathrm{R})$ & 98 & 0.8675 & 0.9218 & 0.5168 & 1.2183 \\
\hline $\mathrm{ZnO}(\mathrm{B})$ & 99 & 1.0784 & 0.9632 & 0.7857 & 1.3711 \\
\hline $\mathrm{ZnO}(\mathrm{O})$ & 100 & 1.9213 & 0.9776 & 1.0355 & 2.8071 \\
\hline
\end{tabular}

The degradation efficiency of MB dye was higher than that of MO after the addition of ZnONPs. During the control experiment, none of the photocatalysts was added. However, after $5 \mathrm{~h}$ of exposure to UV light, the degradation of MB was high, reaching $97 \%$. This happens because the structure of MB generates electrons and forms peroxide radical. These causes degradation, as $\mathrm{MB}$ was very sensitive to light compared to $\mathrm{MO}$ [47]. Besides, degradation rate depends on the number of dye molecules absorbed by the catalyst. MB has a smaller molecular structure compared to $\mathrm{MO}$. In other words, a greater number of dye molecules penetrate the catalyst. Thus, the number of MB dye molecules absorbing and in contact with the surface and pores of $\mathrm{ZnO}$ are more than $\mathrm{MO}$ [48].

The degradation efficiency of synthesized ZnONPs on $\mathrm{MO}$ is as follows: Control $<\mathrm{ZnO}(\mathrm{O})$ $<\mathrm{ZnO}(\mathrm{R})<\mathrm{ZnO}(\mathrm{B})$; while for $\mathrm{MB}$ : control $<\mathrm{ZnO}(\mathrm{R})<\mathrm{ZnO}(\mathrm{B})<\mathrm{ZnO}(\mathrm{O})$. The size of the photocatalysts (ZnONPs) influences the efficiency of photodegradation activity. In a particular system, the decrease in the average particle size increases the rate of the interfacial charge transfer. In other words, smaller particle size is proportional to the enhancement of specific surface area. This then increases the number of active surface sites. In this case, the photogenerated charge carriers react with absorbed molecules to form hydroxyl and superoxide radicals. However, our findings revealed that the photocatalytic activity does not increase monotonically with decrease in the particle size. This might be due to the amplification in the rate of recombination process, thus proportionally raising the activity arising from the greater specific surface area for sufficiently small particle size [19]. 


\subsection{Antioxidant Activity}

Antioxidant activity was carried out by using a DPPH assay with slight modification. The free radical-scavenging capability of ZnONPs was evaluated as shown in Figure 10. DPPH was used in the study because their stable free radical had a strong absorption band at 517-520 nm. The maximum absorption decreases as the radical reacts with the antioxidant content in ZnONPs. The presence of antioxidants turns the purple color of DPPH fade to yellow [49]. DPPH scavenging activity of ZnONPs is shown in Figure 10. The experimental data from ZnONPs with plant extracts demonstrated a higher scavenging activity. The negatively charged bioactive compounds $\left(\mathrm{C}^{-} \mathrm{O}^{-}\right)$that presented in $\mathrm{ZnO}(\mathrm{R})$ and $\mathrm{ZnO}(\mathrm{O})$ reacted with positively charged nanoparticles $\left(\mathrm{ZnO}=\mathrm{Zn}^{2+}+\mathrm{O}^{2-}\right)$ as shown in the figure. The site of attachment of the metals with the antioxidant agents affected the DPPH scavenging activity [50].
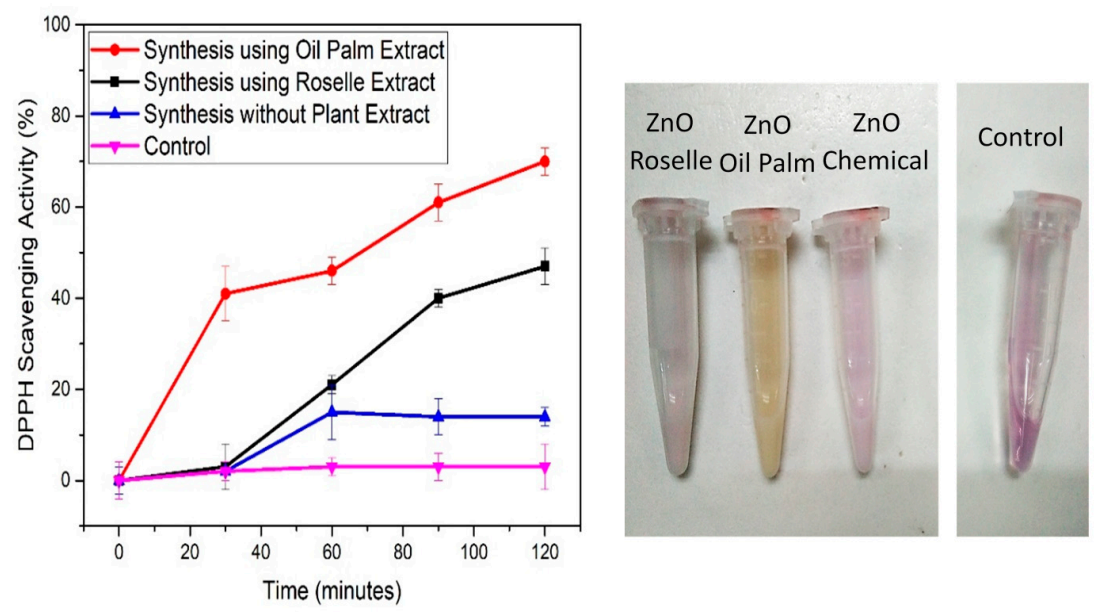

Figure 10. DPPH scavenging activity of synthesized ZnONPs.

\section{Materials and Methods}

\subsection{Materials}

Oil palm leaves and roselle flowers were picked from the estate of Universiti Putra Malaysia, Malaysia. Zinc acetate dihydrate, $\mathrm{Zn}\left(\mathrm{C}_{2} \mathrm{H}_{3} \mathrm{O}_{2}\right)_{2} \bullet 2 \mathrm{H}_{2} \mathrm{O}$ and sodium hydroxide, $\mathrm{NaOH}$ were purchased from R\&M, London, UK. All the reagents used in this study were of analytical grade and used without further purification.

\subsection{Synthesis of Photocatalyst (ZnONPs)}

ZnONPs have been synthesized using modified green methods proposed by Hassan and team in 2015. ZnONPs were synthesized by adding $0.2 \mathrm{~g}$ zinc acetate dihydrate, $\mathrm{Zn}\left(\mathrm{C}_{2} \mathrm{H}_{3} \mathrm{O}_{2}\right)_{2} \bullet 2 \mathrm{H}_{2} \mathrm{O}$ into $50 \mathrm{~mL}$ of distilled water. The solution was stirred to ensure that the zinc acetate dihydrate had dissolved completely. Total of $1 \mathrm{~mL}$ of oil palm leaf and roselle flower extract have been added into the solution respectively. $2 \mathrm{M}$ of sodium hydroxide, $\mathrm{NaOH}$, was added dropwise until the $\mathrm{pH}$ of the solution reached $\mathrm{pH}$ 12. The mixtures were stirred for $2 \mathrm{~h}$ at $250 \mathrm{rpm}$. Precipitates were obtained after centrifuging the mixtures at $6000 \mathrm{rpm}$ for $15 \mathrm{~min}$. The resultant precipitates were washed with distilled water to obtain high purity ZnONPs. Finally, the products were dried at $80^{\circ} \mathrm{C}$ for $24 \mathrm{~h}$. The process was carried out again without addition of plant extract. Products were ready to be used for research purposes as blank control [27].

\subsection{Characterization}

The external morphology of synthesized ZnONPs has been observed. The JEOL 6000 microscope filled with energy dispersive X-ray analyzer (EDX) operating at $1.5 \mathrm{kV}$ accelerating voltage was 
used. Thermo Scientific Talos L120C (UKM, Bangi, Malaysia), transmission electron microscope performed $20 \mathrm{kV}$ thermionic on ZnONPs. High magnification images of internal structure and size of the synthesized ZnONPs have been observed. The crystalline nature and the formation of synthesized ZnONPs were observed using Rigaku X-ray diffractometer (XRD, UPM, Serdang, Malaysia) with $\mathrm{Cu} \mathrm{K}-\alpha$ radiation at $40 \mathrm{kV}$ and $15 \mathrm{~mA}$ with a scan rate of $10^{\circ} / \mathrm{min}$. The samples were measured at $2 \theta$ in the range of $20^{\circ}$ to $80^{\circ}$. Fourier transform infrared spectroscopy (FTIR, Kyutech, Kyushu, Japan) was used to identify the biomolecule and functional group involved in reduction of zinc ion and capping of reduced ZnONPs. Genesys $10 \mathrm{~s}$, Thermo Fisher Scientific was run at wavelengths ranging from 200 to $800 \mathrm{~nm}$. The reduction and UV- vis absorption spectra of zinc ions in ZnONPs were monitored. The samples were diluted in ethanol and sonicated to achieve homogeneity prior to any observation. The thermal decomposition behavior of the synthesized ZnONPs was studied by thermogravimetric analysis. EXSTAR TG/DTA 7000 (Kyutech, Kyushu, Japan), under $\mathrm{N}_{2}$ atmosphere from room temperature to $550^{\circ} \mathrm{C}$ at a rate of $2{ }^{\circ} \mathrm{C} / \mathrm{min}$ was used. JEOL ESR spectrometer (JES-FA 200, UPM, Serdang, Malaysia) was used to obtain electron spin resonance (ESR) spectra. The behavior of present native defects was identified from the spectra. These include oxygen and zinc vacancies.

\subsection{Photocatalytic Activity}

$10 \mathrm{ppm}$ of MO and MB solutions have been prepared. 5\% of each synthesized ZnONPs was added into the dye solution respectively. No ZnONPs sample added to the control study. $10 \mathrm{~W}$ UV-Lamp with $254 \mathrm{~nm}$ wavelength was then immersed into the dye solution and the whole beaker was placed into a box. This step aims to prevent any external light from interrupting the photocatalytic activity. Before the activity begins, the mixture is stirred for $30 \mathrm{~min}$ to achieve equilibrium. The samples are collected within $1 \mathrm{~h}$. The aliquots obtained were centrifuged before determination of the absorbance using UV-Vis. UV-vis absorption spectra of the samples were measured by Xenon Flash Lamp with wavelength of 190-1100 $\mathrm{nm}$ as an excitation light source. The UV-Vis absorption spectra of the aliquots were recorded at $\lambda_{\max }=463 \mathrm{~nm}$ for $\mathrm{MO}$ and $\lambda_{\max }=661 \mathrm{~nm}$ for MB.

\subsection{Antioxidant Activity}

The antioxidant activity was performed using DPPH assay which had been modified by Stan et al. [51]. Total of $20 \mathrm{mg}$ of each ZnONPs was dispersed in $1.3 \mathrm{~mL}$ of DPPH which was prepared in concentration of $100 \mu \mathrm{mol} / \mathrm{L}$ in methanol. The suspensions were stirred by a magnetic stirrer. This is to enhance the surface reaction between synthesized ZnONPs and DPPH reagent. Every $30 \mathrm{~min}$, each suspension was removed for centrifugation. The absorbance of each supernatant was observed by Thermo Fisher Scientific Varioskan Flash. Scavenging percentage was calculated by using Equation (3):

$$
\text { DPPH Scavenging }(\%)=\frac{I}{I o} \times 100 \%
$$

where $I_{o}$ is the initial intensity of the DPPH spectrum while $I$ represented the changed intensity of the DPPH spectrum.

\section{Conclusions}

In summary, ZnONPs were successfully synthesized with roselle flower extract and oil palm leaf extract. SEM mapping and EDX revealed $\mathrm{Zn}$ and $\mathrm{O}$ were presented as the element in the high purity ZnONPs. TEM images confirmed the agglomerated spherical-shaped and size of the nanoparticles. The maximum absorption was observed between 357 and $365 \mathrm{~nm}$ from UV-Vis spectral analysis, corresponding to the intrinsic band gap of ZnONPs. TGA showed high thermal stability of ZnONPs in the range of $30-550{ }^{\circ} \mathrm{C}$. Oxygen has been shown by ESR which is essential in the photocatalytic process. Photocatalytic processes showed that $5 \%$ of ZnONPs with the presence of $10 \mathrm{~W}$ UV light can effectively degrade $\mathrm{MO}$ in $5 \mathrm{~h}$ and $\mathrm{MB}$ in $3 \mathrm{~h}$. High antioxidant properties and low toxicity have been obtained in $\mathrm{ZnO}(\mathrm{R})$ and $\mathrm{ZnO}(\mathrm{O})$ with the presence of natural plant products. In short, ZnONPs are produced 
with a simple, effective, and biosynthetic method. Such eco-friendly ZnONPs can be further developed in a variety of fields. These include water treatment as catalyst, medication, and drug delivery.

Supplementary Materials: The following are available online at http://www.mdpi.com/2073-4344/10/10/1129/s1, Figure S1: Photocatalytic Activity of MO dye: (a) Control; (b) ZnO (B); (c) ZnO (O); (d) ZnO (R), Figure S2: Photocatalytic Activity of MB dye: (a) Control; (b) $\mathrm{ZnO}$ (B); (c) $\mathrm{ZnO}$ (O); (d) $\mathrm{ZnO}$ (R).

Author Contributions: G.E.L., wrote the manuscript, research concept, characterization of materials, photocatalytic activity, interpretation of results; C.A.C.A., wrote the manuscript, critical revision, and supervision of all aspects of the research; W.A.N.W.A., supervision and antioxidant aspect of the research; S.A., determination and interpretation of antioxidant activity; A.L.T.Z., characterization of materials. All authors have read and agreed to the published version of the manuscript.

Funding: This research received no external funding.

Acknowledgments: I have great pleasure in acknowledging my gratitude to Nurul Husna Shafie from the Department of Nutrition and Dietetics who had provided consumables for experiments. In addition, big thank you to fellow researchers in the Biophysics Lab.

Conflicts of Interest: The authors declare no conflict of interest.

\section{References}

1. Kant, R. Textile dyeing industry an environmental hazard. Sci. Res. 2011, 4. [CrossRef]

2. Bhatia, S.; Verma, N. Photocatalytic activity of $\mathrm{ZnO}$ nanoparticles with optimization of defects. Mater. Res. Bull. 2017, 95, 468-476. [CrossRef]

3. Weitzel, T.; Rodriguez, M.F.; Ciapponi, A.; Calderón, M. Methylene blue for treating malaria. Cochrane Database Syst. Rev. 2017. [CrossRef]

4. Cengiz, S.; Cavas, L. Removal of methylene blue by invasive marine seaweed: Caulerpa racemosa var. cylindracea. Bioresour. Technol. 2008, 99, 2357-2363. [CrossRef]

5. Gita, S.; Hussan, A.; Choudhury, T. Impact of textile dyes waste on aquatic environments and its treatment. Environ. Ecol. 2017, 35, 2349-2353.

6. Rai, H.S.; Bhattacharyya, M.S.; Singh, J.; Bansal, T.; Vats, P.; Banerjee, U.J.C. Removal of dyes from the effluent of textile and dyestuff manufacturing industry: A review of emerging techniques with reference to biological treatment. Crit. Rev. Environ. Sci. Technol. 2005, 35, 219-238. [CrossRef]

7. Kumar, A.; Pandey, G. A review on the factors affecting the photocatalytic degradation of hazardous materials. Mater. Sci. Eng. Int. J. 2017, 1, 1-10. [CrossRef]

8. Trandafilović, L.V.; Jovanović, D.J.; Zhang, X.; Ptasińska, S.; Dramićanin, M. Enhanced photocatalytic degradation of methylene blue and methyl orange by ZnO: Eu nanoparticles. Appl. Catal. B Environ. 2017, 203, 740-752. [CrossRef]

9. Siripireddy, B.; Mandal, B.K. Facile green synthesis of zinc oxide nanoparticles by Eucalyptus globulus and their photocatalytic and antioxidant activity. Adv. Powder Technol. 2017, 28, 785-797. [CrossRef]

10. Nagajyothi, P.; Prabhakar Vattikuti, S.; Devarayapalli, K.; Yoo, K.; Shim, J.; Sreekanth, T. Green synthesis: Photocatalytic degradation of textile dyes using metal and metal oxide nanoparticles-latest trends and advancements. Crit. Rev. Environ. Sci. Technol. 2019. [CrossRef]

11. Suresh, J.; Pradheesh, G.; Alexramani, V.; Sundrarajan, M.; Hong, S.I. Green synthesis and characterization of zinc oxide nanoparticle using insulin plant (Costus pictus D. Don) and investigation of its antimicrobial as well as anticancer activities. Adv. Nat. Sci. Nanosci. Nanotechnol. 2018, 9, 015008. [CrossRef]

12. Albiter, E.; Barrera-Andrade, J.M.; Rojas-García, E.; Valenzuela, M.A. Recent Advances of Nanocarbon-inorganic Hybrids in Photocatalysis. In Nanocarbon and Its Composites; Elsevier: Amsterdam, The Netherlands, 2019; pp. 521-588.

13. Samuel, J.J.; Yam, F.K. Photocatalytic degradation of methylene blue under visible light by dye sensitized titania. Mater. Res. Express 2020, 7, 015051. [CrossRef]

14. Gnanasekaran, L.; Hemamalini, R.; Saravanan, R.; Ravichandran, K.; Gracia, F.; Agarwal, S.; Gupta, V.K. Synthesis and characterization of metal oxides $\left(\mathrm{CeO}_{2}, \mathrm{CuO}, \mathrm{NiO}, \mathrm{Mn}_{3} \mathrm{O}_{4}, \mathrm{SnO}_{2}\right.$ and $\left.\mathrm{ZnO}\right)$ nanoparticles as photo catalysts for degradation of textile dyes. J. Photochem. Photobiol. B Biol. 2017, 173, 43-49. [CrossRef]

15. Sabir, S.; Arshad, M.; Chaudhari, S.K. Zinc oxide nanoparticles for revolutionizing agriculture: Synthesis and applications. Sci. World J. 2014. [CrossRef] 
16. Halim, D.; Sihning, E. The Effect of Roselle (Hibiscus sabdariffa Linn) Flower Extract to the SGPT Activity in Male Wistar Rats (Rattus Norvegicus) Induced by High Dose Paracetamol. In Earth and Environmental Science; IOP Conference Series; IOP Publishing: Bristol, UK, 2019; p. 012018.

17. Nasir, S.; Hussein, M.Z.; Yusof, N.A.; Zainal, Z. Oil palm waste-based precursors as a renewable and economical carbon sources for the preparation of reduced graphene oxide from graphene oxide. Nanomaterials 2017, 7, 182. [CrossRef]

18. Shivaji, K.; Monica, E.S.; Devadoss, A.; Kirubakaran, D.D.; Dhas, C.R.; Jain, S.M.; Pitchaimuthu, S. Synthesizing Green Photocatalyst Using Plant Leaf Extract for Water Pollutant Treatment. In Green Photocatalysts; Springer: Berlin, Germany, 2020; pp. 25-46.

19. Dodd, A.; McKinley, A.; Saunders, M.; Tsuzuki, T. Effect of particle size on the photocatalytic activity of nanoparticulate zinc oxide. J. Nanopart. Res. 2006, 8, 43. [CrossRef]

20. Yusof, N.Z.; Abd Gani, S.S.; Siddiqui, Y.; Mohd Mokhtar, N.; Hasan, Z.A. Potential uses of oil palm (Elaeis guineensis) leaf extract in topical application. J. Oil Palm Res. 2016, 28, 520-530. [CrossRef]

21. Heinlaan, M.; Ivask, A.; Blinova, I.; Dubourguier, H.-C.; Kahru, A. Toxicity of nanosized and bulk ZnO, $\mathrm{CuO}$ and $\mathrm{TiO}_{2}$ to bacteria Vibrio fischeri and crustaceans Daphnia magna and Thamnocephalus platyurus. Chemosphere 2008, 71, 1308-1316. [CrossRef]

22. Hasnidawani, J.; Azlina, H.; Norita, H.; Bonnia, N.; Ratim, S.; Ali, E. Synthesis of ZnO nanostructures using sol-gel method. Procedia Chem. 2016, 19, 211-216. [CrossRef]

23. Küünal, S.; Rauwel, P.; Rauwel, E. Plant extract mediated synthesis of nanoparticles. In Emerging Applications of Nanoparticles and Architecture Nanostructures; Elsevier: Amsterdam, The Netherlands, 2018; pp. 411-446.

24. Osuntokun, J.; Onwudiwe, D.C.; Ebenso, E.E. Green synthesis of ZnO nanoparticles using aqueous Brassica oleracea L. var. italica and the photocatalytic activity. Green Chem. Lett. Rev. 2019, 12, 444-457. [CrossRef]

25. Chaudhary, A.; Kumar, N.; Kumar, R.; Salar, R.K. Antimicrobial activity of zinc oxide nanoparticles synthesized from Aloe vera peel extract. SN Appl. Sci. 2019, 1, 136. [CrossRef]

26. Yedurkar, S.; Maurya, C.; Mahanwar, P.A. A biological approach for the synthesis of copper oxide nanoparticles by Ixora coccinea leaf extract. J. Mater. Environ. Sci. 2017, 8, 1173-1178.

27. Hassan, S.S.; El Azab, W.I.; Ali, H.R.; Mansour, M.S. Green synthesis and characterization of ZnO nanoparticles for photocatalytic degradation of anthracene. Adv. Nat. Sci. Nanosci. Nanotechnol. 2015, 6, 045012. [CrossRef]

28. Vijayakumar, S.; Arulmozhi, P.; Kumar, N.; Sakthivel, B.; Kumar, S.P.; Praseetha, P. Acalypha fruticosa L. leaf extract mediated synthesis of $\mathrm{ZnO}$ nanoparticles: Characterization and antimicrobial activities. Mater. Today Proc. 2019, 23, 73-80. [CrossRef]

29. Ji, W.; Zhu, D.; Chen, Y.; Hu, J.; Li, F. In-vitro cytotoxicity of biosynthesized Zinc oxide nanoparticles towards cardiac cell lines of Catla catla. Boimed. Res. 2017, 28, 2262-2266.

30. Raj, A.; Lawerence, R. Green synthesis and charcterization of zno nanoparticles from leafs extracts of rosa indica and its antibacterial activity. Nutrition 2018, 11, 1339-1348. [CrossRef]

31. Kumar, B.; Smita, K.; Cumbal, L.; Debut, A. Green approach for fabrication and applications of zinc oxide nanoparticles. Bioinorg. Chem. Appl. 2014. [CrossRef]

32. Chanayath, N.; Lhieochaiphant, S.; Phutrakul, S.J. Pigment extraction techniques from the leaves of Indigofera tinctoria Linn. and Baphicacanthus cusia Brem. and chemical structure analysis of their major components. Chiang Mai Univ. J. 2002, 1, 149-160.

33. Patil, B.N.; Taranath, T.C. Limonia acidissima L. leaf mediated synthesis of zinc oxide nanoparticles: A potent tool against Mycobacterium tuberculosis. Int. J. Mycobacterial. 2016, 5, 197-204. [CrossRef]

34. Varughese, G.; Jithin, P.; Usha, K. Determination of optical band gap energy of wurtzite ZnO: Ce nanocrystallites. Phys. Sci. Int. J. 2015, 5, 146-154. [CrossRef]

35. Sengupta, A.; Sarkar, C.K. Introduction to Nano: Basics to Nanoscience and Nanotechnology; Springer: Berlin, Germany, 2015.

36. Gupta, P.; Ramrakhiani, M. Influence of the particle size on the optical properties of CdSe nanoparticles. Open Nanosci. J. 2009, 3, 15-19. [CrossRef]

37. Brus, L. Electronic wave functions in semiconductor clusters: Experiment and theory. J. Phys. Chem. 1986, 90, 2555-2560. [CrossRef]

38. Jayappa, M.D.; Ramaiah, C.K.; Kumar, M.A.P.; Suresh, D.; Prabhu, A.; Devasya, R.P.; Sheikh, S. Green synthesis of zinc oxide nanoparticles from the leaf, stem and in vitro grown callus of Mussaenda frondosa L.: Characterization and their applications. Appl. Nanosci. 2020. [CrossRef] 
39. Tomaszewska, E.; Soliwoda, K.; Kadziola, K.; Tkacz-Szczesna, B.; Celichowski, G.; Cichomski, M.; Szmaja, W.; Grobelny, J. Detection limits of DLS and UV-Vis spectroscopy in characterization of polydisperse nanoparticles colloids. J. Nanomater. 2013. [CrossRef]

40. Ferreira-Neto, E.P.; Worsley, M.A.; Rodrigues-Filho, U.P. Towards thermally stable aerogel photocatalysts: TiCl4-based sol-gel routes for the design of nanostructured silica-titania aerogel with high photocatalytic activity and outstanding thermal stability. J. Environ. Chem. Eng. 2019, 7, 103425. [CrossRef]

41. Acosta-Humánez, F.; Pitalúa, R.C.; Almanza, O. Electron paramagnetic resonance in Zn1- xCoxO. J. Magn. Magn. Mater. 2013, 329, 39-42. [CrossRef]

42. Acosta-Humánez, M.; Montes-Vides, L.; Almanza-Montero, O. Sol-gel synthesis of zinc oxide nanoparticle at three different temperatures and its characterization via XRD, IR and EPR. Dyna 2016, 83, 224-228. [CrossRef]

43. Nguyen, C.H.; Fu, C.-C.; Juang, R.-S. Degradation of methylene blue and methyl orange by palladium-doped $\mathrm{TiO}_{2}$ photocatalysis for water reuse: Efficiency and degradation pathways. J. Clean. Prod. 2018, 202, 413-427. [CrossRef]

44. Kazeminezhad, I.; Sadollahkhani, A. Influence of $\mathrm{pH}$ on the photocatalytic activity of $\mathrm{ZnO}$ nanoparticles. J. Mater. Sci. Mater. Electron. 2016, 27, 4206-4215. [CrossRef]

45. Thongam, D.D.; Gupta, J.; Sahu, N.K. Effect of induced defects on the properties of ZnO nanocrystals: Surfactant role and spectroscopic analysis. SN Appl. Sci. 2019, 1, 1030. [CrossRef]

46. Reed, A.E.; Weinhold, F. Natural bond orbital analysis of near-Hartree-Fock water dimer. J. Chem. Phys. 1983, 78, 4066-4073. [CrossRef]

47. Nakkala, J.R.; Mata, R.; Sadras, S.R. The antioxidant and catalytic activities of green synthesized gold nanoparticles from Piper longum fruit extract. Process Saf. Environ. Prot. 2016, 100, 288-294. [CrossRef]

48. Kumar, B.; Smita, K.; Cumbal, L.; Debut, A. Synthesis of silver nanoparticles using Sacha inchi (Plukenetia volubilis L.) leaf extracts. Saudi J. Biol. Sci. 2014, 21, 605-609. [CrossRef] [PubMed]

49. Ullah, A.; Ullah, S.; Khan, M.Q.; Hashmi, M.; Nam, P.D.; Kato, Y.; Tamada, Y.; Kim, I.S. Manuka honey incorporated cellulose acetate nanofibrous mats: Fabrication and in vitro evaluation as a potential wound dressing. Int. J. Biol. Macromol. 2020, 155, 479-489. [CrossRef] [PubMed]

50. Kumar, B.; Smita, K.; Cumbal, L.; Debut, A.; Angulo, Y. Biofabrication of copper oxide nanoparticles using Andean blackberry (Rubus glaucus Benth.) fruit and leaf. J. Saudi Chem. Soc. 2017, 21, S475-S480. [CrossRef]

51. Stan, M.; Popa, A.; Toloman, D.; Silipas, T.-D.; Vodnar, D.C. Antibacterial and antioxidant activities of ZnO nanoparticles synthesized using extracts of Allium sativum, Rosmarinus officinalis and Ocimum basilicum. Acta Metall. Sin. (Engl. Lett.) 2016, 29, 228-236. [CrossRef] 